\title{
Mitochondrial DNA maintenance in yeast requires a protein containing a region related to the GTP-binding domain of dynamin
}

\author{
Bryan A. Jones ${ }^{1}$ and Walton L. Fangman \\ Department of Genetics SK-50, University of Washington, Seattle, Washington 98195 USA
}

\begin{abstract}
Nuclear gene products replicate and partition mitochondrial DNA (mtDNA) molecules in the yeast Saccharomyces cerevisiae. However, few of the relevant genes have been identified. A mutation that results in temperature-sensitive loss of mtDNA identifies one of these genes, MGM1. Deletion of MGM1 shows that aside from its role in the mitochondrion, the gene has no essential cellular function. The MGM1 protein has a 200-amino-acid region that is highly related to a family of GTP-binding proteins of apparently diverse function that includes the microtubule-binding protein, dynamin D100. The temperature-sensitive strain partitions mtDNA molecules at the restrictive temperature, but a defect in mtDNA synthesis results in a reduction in the number of molecules per cell at each cell division. On the basis of the results of this study, we conclude that cells can partition single mitochondrial genomes, and that when a cell receives a single molecule at division it is able to restore the normal complement of multiple copies.
\end{abstract}

[Key Words: Saccharomyces cerevisiae; mitochondrion; DNA replication; DNA segregation; GTP binding; dynamin]

Received October 21, 1991; revised version accepted January 15, 1992.

The mitochondrial genome of eukaryotic organisms is maintained by the products of nuclear genes that supply the machinery for replication and partition to daughter cells at division. The mitochondrial genome of Saccharomyces cerevisiae has been studied extensively because cells can grow by fermentation in the absence of respiratory function. The ability to grow without a functional mitochondrial genome has greatly facilitated mutant analysis. Several laboratories have identified mutations in nuclear genes, called PET genes, that affect respiratory competence (for review, see Tzagoloff and Dieckmann 1990). Thus far, only a small subset of the PET genes have been found to be involved in the maintenance of the mitochondrial genome: MIP1 coding for DNA polymerase (Foury 1989), PPA2 encoding a pyrophosphatase (Lundin et al. 1991), and $A B F 2$ coding for a DNA-binding protein (Diffley and Stillman 1991).

We are using a simple mutant screen to identify additional nuclear genes required for the maintenance of mitochondrial DNA (mtDNA) in S. cerevisiae. Here, we report the analysis of one of these mitochondrial genome maintenance genes, MGM1. The predicted MGM1 protein contains a 200 -amino-acid region that is highly related to a family of putative GTP-binding proteins and

${ }^{1}$ Present address: Bristol-Myers Squibb, Pharmaceutical Research Institute, Seattle, Washington 98121 USA. includes the microtubule-binding protein dynamin D100. A mutation in MGM1 results in the temperaturesensitive loss of mtDNA molecules. At the restrictive temperature, mutant cells appear to partition their mtDNA molecules normally but mtDNA synthesis is blocked.

\section{Results \\ Identification and mapping of the MGMl gene}

We used a novel, simple screen to identify mutants defective in mitochondrial genome maintenance. Certain adenine-requiring strains produce a red pigment and form red colonies on YEPD medium, provided that the cells can respire. Cells that have lost the ability to respire form white colonies (Reaume and Tatum 1949). The change in colony color accompanying the loss of respiration competence allows an easy first step to identify the mutants of interest. An ade1 ade2 strain, BS127, was mutagenized with ethylmethanesulfonate (EMS) and plated at $23^{\circ} \mathrm{C}$. Individual colonies were streaked onto plates and incubated at $36^{\circ} \mathrm{C}$. Clones that produced a high frequency of white sectors at $36^{\circ} \mathrm{C}$ were subsequently tested for their inability to grow on glycerol at $36^{\circ} \mathrm{C}$ to confirm that they give rise to respiration-deficient cells. Cells in the white colonies formed by these 
temperature-sensitive mutants were screened by DAPI staining for the absence of chondriolites, the bright spots of cytoplasmic fluorescence indicative of mtDNA (Williamson 1976; Williamson and Fennel 1979). (Cells lacking mtDNA are called $\rho^{\circ}$.) This paper characterizes one of these mutations, $m g m 1-1$. It is recessive and, in meiosis, segregates $2: 2$ for the temperature-sensitive phenotype, the pattern expected for a nuclear gene.

Hybridization of the cloned MGM1 gene (see below) to yeast chromosomal DNAs separated by pulse-field gel electrophoresis (Carle and Olson 1984) indicated that the gene maps to one of two unresolved chromosomes, VII or $\mathrm{XV}$ (data not shown). Genetic crosses revealed linkage to markers on the right arm of chromosome $\mathrm{XV}$, and a fourfactor cross with his 3 , met7, ade2, and mgm1-1 showed that MGM1 is $12 \mathrm{cM}$ centromere-distal of HIS 3 and 27 cM proximal of MET7 (88 tetrads examined). Southern analysis and sequence comparisons with other cloned genes in this region show that MGM1 is a previously unidentified gene located in a cluster of known genes. Beginning with the gene closest to the centromere, the order of the genes in the cluster is PET56-HIS3-DED1RET1-PTP1-MGM1-STE4-MET7 (Fig. 1; James et al. 1991).

\section{Segregation of mtDNA in the absence of synthesis}

When a culture of $m g m 1-1$ cells is transferred from 23 to $34^{\circ} \mathrm{C}$, cells that yield white (respiration-deficient) colonies at $23^{\circ} \mathrm{C}$ are not produced for $4.0-4.25$ generations $(\sim 5 \mathrm{hr})$; subsequently, they appear at a rate of $50 \%$ per cell per division (Fig. 2). Samples of the culture transferred from 23 to $34^{\circ} \mathrm{C}$ were also stained directly with DAPI. Cells lacking chondriolites appear with kinetics similar to those for white colonies (Fig. 2), indicating that the mitochondrial genotype is already $\rho^{\circ}$ at the time a cell destined to form a white colony is returned to the permissive temperature. These observations are consistent with a defect in which $\mathrm{mtDNA}$ replication ceases at $34^{\circ} \mathrm{C}$ and the preexisting mtDNA molecules are diluted

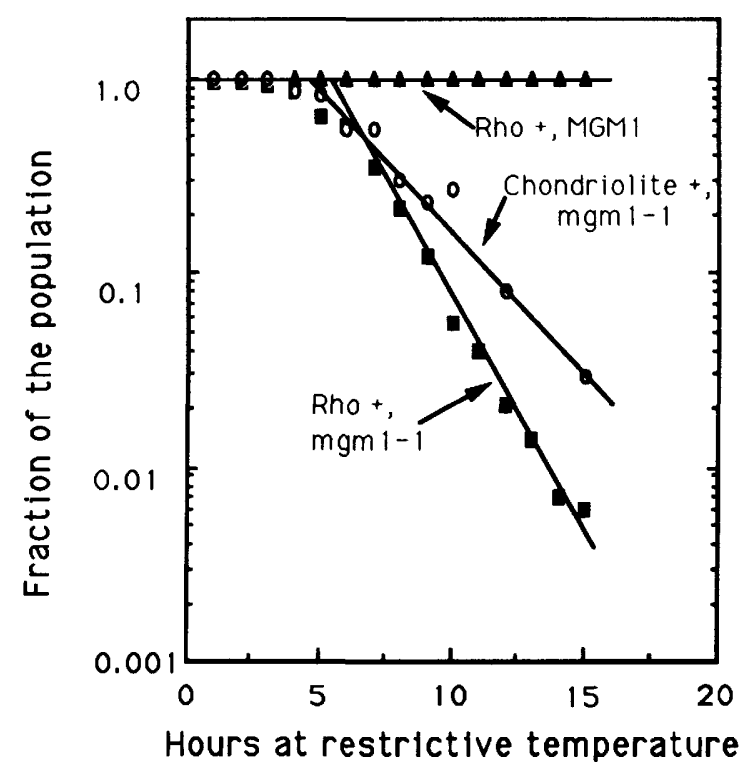

Figure 2. Rate of white $\left(\rho^{\circ}\right)$ colony formation when cells are grown at the restrictive temperature. The fraction of the population that still forms red (respiration-competent) colonies is plotted vs. the amount of time at the restrictive temperature. During the course of the experiment, both the MGM1-1 and mgm1-1 strains grew at the same rate, $75-80 \mathrm{~min} /$ generation. The apparent frequency of cells containing mtDNA in the mgm 1-1 culture, as determined by DAPI staining, is also shown (chondriolite + cells).

by subsequent cell divisions. Direct support for this interpretation is provided by two experiments. First, a mgm1-1 culture was transferred from 23 to $34^{\circ} \mathrm{C}$, samples were taken at different times and stained with DAPI, and the number of chondriolites per cell was counted. Figure 3 shows that the average number of chondriolites per cell begins to decline during the first hour of incubation, well before white colony-forming cells arise. If the mutation resulted in the failure of chon-

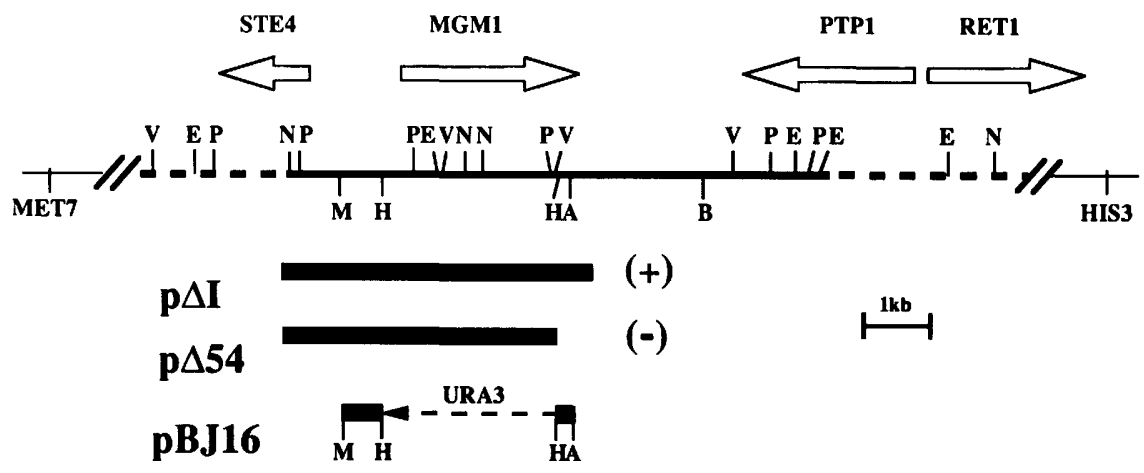

Figure 1. Map of the region of chromosome XV that contains MGM1. The clone containing MGM1 overlapped with clones containing STE4 (Whiteway et al. 1989) and PTP1/RET1 (James et al. 1991). The solid line represents the original clone containing MGM1, and the broken lines represent the flanking DNA defined by the other two clones. Restriction sites that can be used to align the clones are shown above the line. Below the line are several additional restriction sites relevant to the construction of the three plasmid inserts. $\mathrm{p} \Delta \mathrm{I}$ and $\mathrm{p} \Delta 54$ were among a series of plasmids generated by cutting at the BgIII site and making a series of deletions using exonuclease III. p $\Delta \mathrm{I}$ was the largest deletion that was still able to complement the mgm1-1 defect. The insert in this plasmid was sequenced (see Materials and methods). p $\Delta 54$ was the smallest deletion that could no longer complement the mgm1-1 defect. The right end of the deletion lies between the PstI and the PvuII sites (22 bp apart, 80-88 amino acids from the carboxyl terminus). The URA3 substitution-insert in pBJ16 is not drawn to scale. A MluI-AhaII digest of pBJ16 liberates a linear fragment that can be used to delete the chromosomal copy of MGM1 (see Materials and methods). (V) PvuII; (E) EcoRI; (P) PstI; (N) HindIII; (B) BgIII; (H) HpaI; (M) MluI; (A) AhaII. 

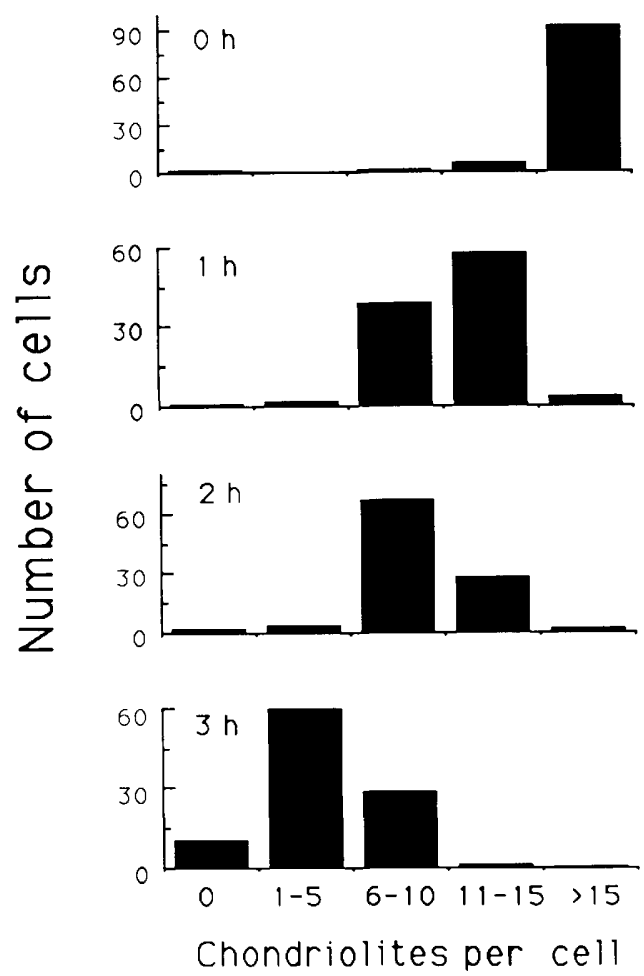

Figure 3. Reduction in the number of chondriolites per cell on incubation at the restrictive temperature. All samples in the experiment were "blind" coded and scored before they were identified.

driolites to segregate, with one product of a cell division receiving all or most of the chondriolites and the other cell receiving few or none, a bimodal distribution of chondriolites per cell would be observed after growth at $34^{\circ} \mathrm{C}$. That the mtDNA is approximately evenly partitioned between dividing cells was confirmed by fluorescence microscopy of DAPI-stained mitotic cells (defined as cells with a large bud, where the nucleus is located in the neck between the mother and daughter cells or is elongated, extending between the mother and daughter cell). Figure 4A shows an example of a wild-type cell, and Figure 4B shows an example of a mgm1-1 cell from a culture that has been at $34^{\circ} \mathrm{C}$ for 2.5 generations. Both show approximately equal mtDNA staining in the mother cell and in the smaller daughter bud. During the course of this work, $>2000$ mitotic mgm1-1 cells taken during the first one to six generations after transfer to $34^{\circ} \mathrm{C}$ were examined; not a single example was observed with an asymmetric distribution of mtDNA. [As a control, we examined wild-type cells treated with acriflavine. Treatment of yeast with acriflavine produces cell divisions in which the daughter cell frequently becomes $\rho^{\circ}$ (Ephrussi and Hottinguer 1951; Mattick and Nagley 1977). In cultures growing in the presence of acriflavine, we observed a large fraction of mitotic cells with an asymmetric distribution of chondriolites (an example is shown in Fig. 4D) consistent with a failure of mtDNA segregation.]
Quantitative hybridization was used in a second experiment to show directly that net mtDNA synthesis ceases quickly in the mgm1-1 culture at the restrictive temperature. Total DNA was prepared from samples taken at different times after the transfer to $34^{\circ} \mathrm{C}$. The DNA was slot-loaded onto filters and hybridized to a probe for a single-copy nuclear sequence (MGM1) and, after stripping, to a probe for mtDNA $(C O B)$ (data not shown). Densitometric analysis showed that the amount of mtDNA per cell (mtDNA/nuclear DNA signal) begins to decline immediately after transfer of $m g m 1-1$ cells to $34^{\circ} \mathrm{C}$ : It decreased to $34 \%$ of the initial value by $6 \mathrm{hr}$ and to $14 \%$ by $12 \mathrm{hr}$. There was no effect on the level of the $2 \mu$ plasmid, a native, nuclear, extrachromosomal element. The decline in mtDNA per cell in the mgm1-1 mutant is explained most simply by a defect in mtDNA replication.

Quantitative hybridization analysis (Materials and methods) of mgm1-1 cells growing at the permissive temperature showed that they contain $14 \pm 5.2$ (three determinations/ mtDNA molecules per cell. The approximately four-generation lag in appearance of respirationdefective cells at $34^{\circ} \mathrm{C}$ (see Fig. 2), combined with the observations of an immediate decline in chondriolites per cell (see Fig. 3) and of a cessation in mtDNA synthesis, must mean that there is nearly equal partitioning of these molecules at each cell division. Therefore, cells that remain capable of forming respiration-competent colonies after four generations contain only one or a few mtDNA molecules. To determine whether the normal amount of mtDNA is restored in clones formed from these cells, nine respiration-competent colonies were picked from $23^{\circ} \mathrm{C}$ platings of cultures that had been incubated for 9.5 generations at $34^{\circ} \mathrm{C}$. A single quantitative analysis on cultures grown up from each of these colonies gave copy numbers similar to those found initially (range: 8-22 per cell; $14 \pm 4.0$ ).

\section{Effects of MGM1 deletion}

The MGM1 gene was cloned by transforming a mgm1 strain with a $2 \mu$ plasmid library (Carlson and Botstein 1982) and selecting for complementation of the mgm1-1 mutation by plating on glycerol plates at $36^{\circ} \mathrm{C}$. Subcloning and deletion analysis of the insert indicated that the complementing activity was confined to a $4.5-\mathrm{kb}$ fragment (p $\Delta \mathrm{I}$; see Fig. 1). This fragment was sequenced (Materials and methods) and found to contain an open reading frame of $2.5 \mathrm{~kb}$ encoding an 843-amino-acid protein (Fig. 5). The only other open reading frames in the fragment coded for no more than 60-70 amino acids. To determine the phenotype of a cell deleted for this gene, a 2.7-kb HpaI-HpaI fragment containing all codons except those for the carboxy-terminal 55 amino acids was removed from the cloned insert and replaced with a 1.3-kb fragment containing the $U R A 3$ gene (pBJ16; see Fig. 1). A 2.1-kb linear MluI-Ahall fragment (see Fig. 1), now containing the URA3 substitution, was transformed into diploid yeast cells. Twenty-eight meiotic tetrads from 

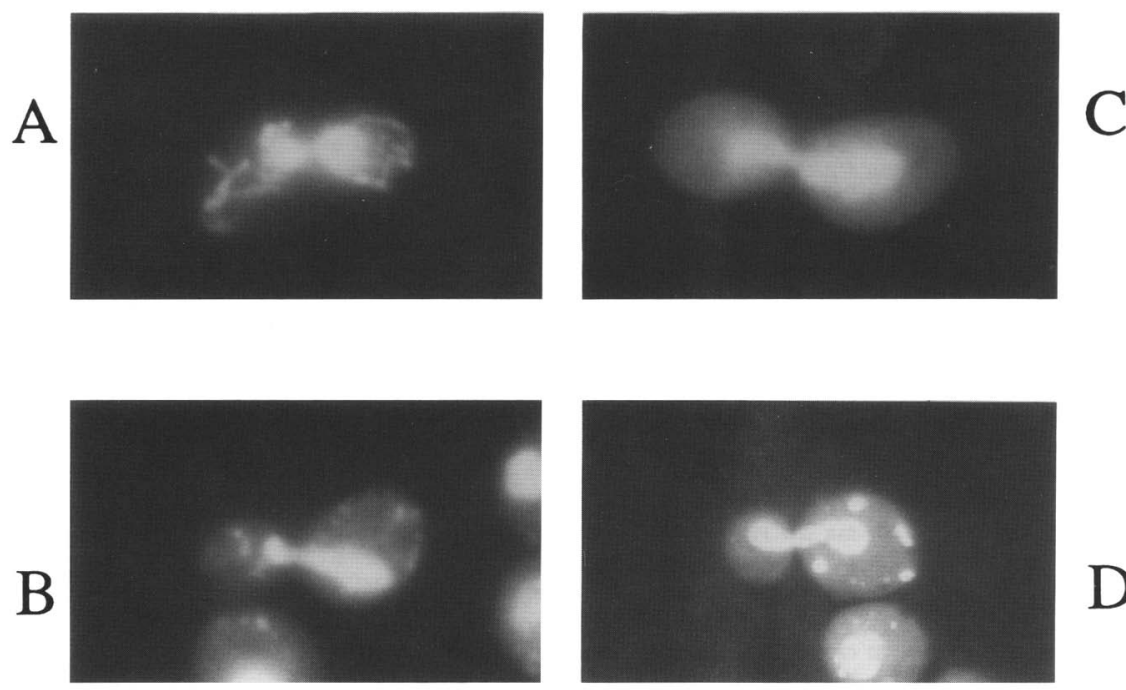

Figure 4. DAPI-stained cells undergoing mitosis. (A) An MGM1 cell displays a brightly staining nucleus in the neck of the bud. The chondriolites are evenly distributed between the mother and the daughter. (B) An mgm1-1 cell grown at the restrictive temperature for 2.5 generations. Chondriolites are evenly distributed between the mother and the daughter cell. (C) An mgm1-1 cell that has become irreversibly respiration deficient. The brightstaining nucleus is still present, but the chondriolites are no longer visible. $(D)$ MGM1 cells grown in the presence of 5 $\mu \mathrm{g} / \mathrm{ml}$ of acriflavine have an asymmetric distribution of chondriolites when the nucleus is in the neck of the bud. six independent diploid transformants were examined. In all tetrads, the $\mathrm{Ura}^{+}$phenotype, which signals the MGM1 deletion, segregated with respiration deficiency and the loss of chondriolites. Southern analysis of two complete tetrads showed that the Ura ${ }^{+}$spores contained the expected deletion-substitutions (data not shown). The only phenotypes observed in the deletion strains were the loss of mtDNA, respiration deficiency, and a reduced rate of growth on glucose medium that is typical of respiration-deficient cells. These results indicated that the deleted gene has no essential cellular function other than maintaining respiration competence.

Because genetic mapping shows that the mgm1-1 mutation is located between HIS3 and MET7, and the restriction map and the sequence of the cloned insert that complements mgm1-1 includes part of the STE4 gene that maps to the same region (see Fig. 1), it seemed likely that the cloned sequence is the structural gene for MGM1. The cloning vector is a high-copy-number plasmid, however, and the possibility remained that the clone does not contain MGM1 but, instead, a closely linked gene that can suppress the mgm1-1 defect when its product is overproduced. We proved that the cloned sequence corresponds to MGM1 by showing that a chromosome with the $U R A 3$ deletion-substitution does not complement the defective mgm1-1 allele.

The wild-type $\left(\rho^{+}\right)$mitochondrial genome gives rise to deletion variants at high frequency. Some of these $\rho^{-}$ genomes may be replicated by a mechanism that cannot be used efficiently by the $\rho^{+}$genome (Fangman et al. 1990). Therefore, their maintenance might not be dependent on MGM1. We examined the replication of two $\rho^{-}$ genomes, $\rho^{-}$HS3324 and $\rho^{-} 4 \mathrm{a}$. $\rho^{-}$HS3324 contains one of the rep (or ori) sequences thought to be a major replication origin; $\rho^{-} 4$ a lacks rep sequences and consists of a simple 64-bp 100\% $\mathrm{A}+\mathrm{T}$ repeated sequence (Fangman et al. 1989). mtDNA was lost when MGM1 was deleted from strains containing each of these $\rho^{-}$mtDNAs /data not shown), indicating that at least some $\rho^{-}$genomes require $M G M 1$ for their maintenance.

\section{Features of the MGM1 protein sequence}

The polypeptide predicted from the sequence of the MGM1 gene is 843 amino acids long (Fig. 5) with a mass of $\sim 94 \mathrm{kD}$. The carboxy-terminal $80-88$ amino acids appear to be essential for function, as deletion of this material from the cloned gene results in a plasmid, $\mathrm{p} \Delta 54$ (see Fig. 1), that fails to complement the mgm1-1 mutation even at a high copy number. The amino acid sequence of the predicted amino terminus of the MGM1 protein is consistent with that of proteins targeted to the mitochondrion. Targeting sequences are 10-70 amino acids long. They are rich in positively charged and hydroxylated amino acids and contain a potential amphiphilic helix (Gavel et al. 1988; Hartl and Neupert 1990). The first 50 amino acids of the MGM1 protein fits this description, with amino acids $18-36$ potentially forming an amphiphilic helix with a hydrophobic moment of 13.8 (von Heijne 1986), among the highest of proteins known to be imported into mitochondria.

Part of the deduced MGM1 protein is highly related to three other proteins of apparently diverse function: the dynamin D100 protein from vertebrates and Drosophila (Obar et al. 1990; Chen et al. 1991; van der Bliek and Meyerowitz 1991), Mx protein found in vertebrates (Arnheiter and Meier 1990), and the VPS1, or SPO15, protein found in yeast (Rothman et al. 1990; Yeh et al. 1991). All four proteins are highly related within two closely spaced blocks (A and B) that span $\sim 200$ amino acids (Figs. 6 and 7). The A block, near the amino terminus, is 45 amino acids long and $52 \%$ identical among all four proteins, allowing no gaps. Comparison of MGM1 with each of the other three proteins shows $61-67 \%$ identities. Between the A block and the B block there is a region of $\sim 35$ amino acids (70 amino acids in VPS1) where the proteins share little similarity. After this short gap, the B block extends for the next 165 amino acids and is $23 \%$ identical among all four proteins, with MGM1 ranging from $30 \%$ to $41 \%$ identical in pairwise comparisons. 


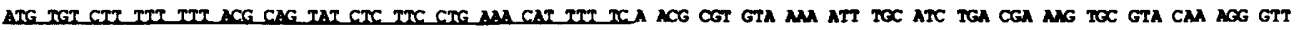
GTG GTC CCA MMA GAG GTA GTA CAC OCC GAG MAT TTG CAC MOG GTA CTG GTT ACA MM GGT MA TAC OOC ФCA OOG ACG GTT GM OCT ATT GM TCT TCG TCT CAT COG CTG ATA TCA AM TCC GAT CAT ACA TAC CCA TCT CM TCT CM TM TTG MCA TTT CAT TTA GCC AGA GM GM CAT CGA CMA GTA NOC TGT TCT TCT OCT COC TM TEG TMA ATG AAG TAG TOG CTC TTA NGT MAT TAT NM TAG TAC ATC TCT CTC AOC GG TGA CAT ATT GTG ATA AM TTT TM COC NOG TGT CAG TMA ATA ACA GNG TTG TM TTA GTT TTA ACT GCA NM GAC TIC OCA AAG AAC ATA TGG COG GGT TTA TCC TTG AM MA CGG TTT CCA TAG GM OCC TMA MT ATG MAT OGA TCT NGT GTA CTC TTT GAG GM ATA TAT TTC AAA TAT TTC TGT CCA TGA AMG ATT TAC TAT GM ATT AMC CCT CAT TCA COG CTT COT ATT OGA TGA TCA ATA TOC NAG TTG TTA ATA TTT OCT TGT ACC GTT NM NC AM ATA GTA GCG TTC TAT TGA MA OCA AGA CAT MAT CAG CTA OGA MOG TTC NCA CCA GTT MAC GGG AGA ACA CGA AAA NOC CTC TTT TTG GGT NGT ACA GAT ATC ATT TTA TTC TTA GOC TIT TOC ATT CTT TTC GTA CTT ATA ATA THG CCT COC ATA TTC ACC ATA ATA CTC TGA AMG CAT GAG TMA TTC TAC TTC ATT AAG GOC CAT COC MM NGT OOC GM CTA TM CAC ATT MGT MG GAT GM TEC GAC CCA GTA CGG CTT TTA ATT CTG AGA AGA CAG CTT OCT ACG CAT CCG OOG ATA CTA TAT NGC TCT OCT TAC ATC MM NGT COG TTG GTG CAC

$-913$

$-823$

$-733$

$-553$

$-463$

$-373$

$-283$

$-193$

TTA CAC HOC COC ATG hOC AAT GTT CAC AGA TCA OCA CAT QCC MT GCT TIG AGT TTT GTT ATC NCC NGG NGA TCG ATA TCA CAT TTT OCT

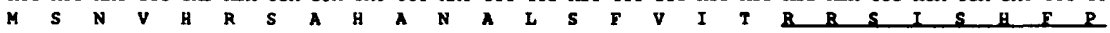
AMA ATT ATA TCT AM ATT ATT AGG ITA CCC ATA TAT GTG GGT GOC GOG ATG GCT OCT OCA GOG NGT TAT ATA GCT IAT AAG ATG GM GM

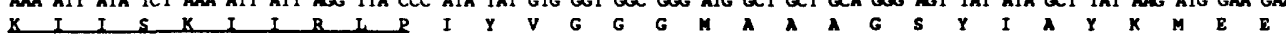
GCT NOC TCT TTT ACT MG GAC MM CTA GAT CGA ATC AAG GAT TTA GGT GM TOG ATG MG GM NG TTT MAT MA ATG TTT TCC GGT GAT $\begin{array}{lllllllllllllllllllllllllllllll}A & S & S & F & T & K & D & K & L & D & R & I & K & D & L & G & E & S & M & K & E & K & F & N & K & M & F & S & G & D\end{array}$ NAG TCA CM GAC TGT GGT CAT GGA MAC GAT GGA MOG GTG CCA MCT OCT NCT CTA ATA GOC QCT ACA TCA CTC GAC GAT GAC GM AGT MAG

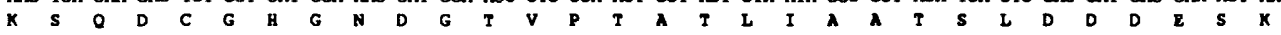
AGG CM GGA GAT CCT MA GAT GAT GAC GAC GM GAT GAT GAT GAC GAG GAT GAT GM NA GAT TCT GTA GAT MCA MOG CM GAC GM ATC

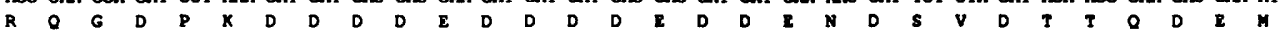
TTA NAC TTA ACC MM CM ATG ATT GM ATT AGA ACT ATT TTG MAT AM GTG GAC TCT TCT TCT OCA CAT TTA ACT TTA OCA TCT ATT GTC $\begin{array}{llllllllllllllllllllllllllllllll}L & N & L & T & K & 0 & M & I & E & I & R & T & I & L & N & K & V & D & S & S & S & A & B & L & T & L & P & S & I & V\end{array}$ GTG ATA @GT TCA CM TCG TCT GGT MA TCC TCA GTA CTA GM TCC ATT GTT COS NOG GM TTC TTA OCA MM OGT TOC AAC ATG GTC ACA $\begin{array}{lllllllllllllllllllllllllllllllll}V & I & G & S & Q & S & S & G & K & S & S & V & L & E & S & I & V & G & R & E & F & L & P & K & G & S & N & M & V & T\end{array}$

AGA NGA CCC ATT GM TTG ACT TTG GTC MAT ACA CCT MA TCG MT MT GTA ACA OCT GAT TTT CCA AOC ATG CGT CTA TAC MAT ATC MAC $\begin{array}{lllllllllllllllllllllllllllllll}R & R & P & I & E & L & T & L & V & N & T & P & N & S & N & N & V & T & A & D & F & P & S & M & R & L & Y & N & I & K\end{array}$ GAC TTT AM GAG GTG AMA AGA ATG CTA ATG GAA CTG NAC ATG OOC GTT OOG ACT TCA GAG OCT GTT TCA GAG GAG CCT ATT CMA ITT ACA

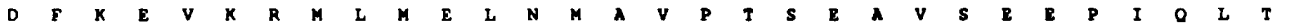

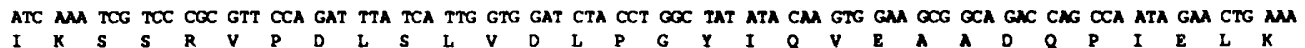
ACA MA ATC CGT GAC CTC TOC GA AAN TAT TTG ACT OCA CCT MAT ATT ATT TTA ФCA ATT TCT @CT OOG GAT GTT GAC CTS @TT MT AGT $\begin{array}{lllllllllllllllllllllllllllllllllll} & K & I & I & R & D & L & C & E & K & Y & L & I & A & P & N & I & I & L & A & I & S & A & A & D & V & D & L & A & N & S\end{array}$

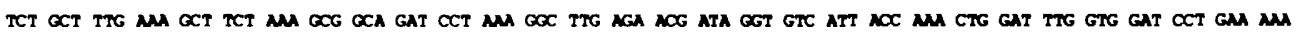

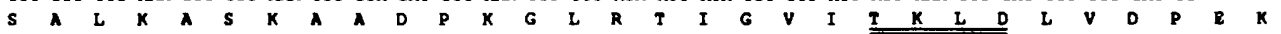
OCA MGA NOC ATC TTG MT MT MM MA TAT CCT CTC NGT ATG GOC TAT GTA OGA GTG ATT ACT MG MCA OCA MGT MGT ATA NAC MGA MU

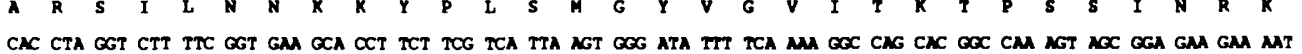

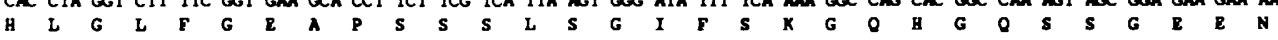
ACC MT GGT TTA MA CM ATT GTG TCT CAT CM TTT GM MM ФCT TAT TTC MA GM MC MM MG TAT TTT MOC MT TOC CM GTT TCC $\begin{array}{llllllllllllllllllllllllllllll}T & N & G & L & K & Q & I & V & S & H & 0 & F & E & K & A & Y & F & K & R & N & K & K & Y & F & T & N & C & 0 & V & S\end{array}$ ACT NAG MN TTG NGA GM NAG TTG ATC NM ATC TTG GAG ATT TCC ATG TCA MAT COG CTG GAG COG MCT TCA NCA CTT ATT CM CM GA

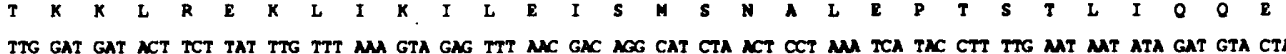
$\begin{array}{llllllllllllllllllllllllllllllll}L & D & D & T & S & Y & L & F & K & V & E & F & N & D & R & A & L & I & P & X & S & Y & L & L & N & N & I & D & V & L\end{array}$

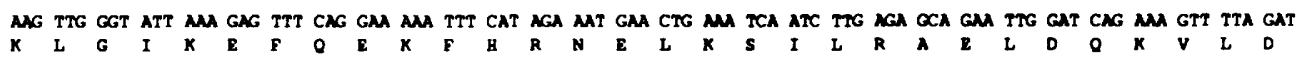

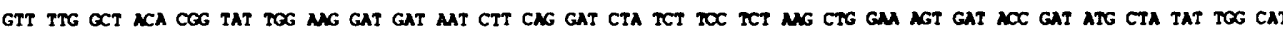
$\begin{array}{lllllllllllllllllllllllllllllllll} & L & A & T & R & Y & W & K & D & D & N & L & 0 & D & L & S & S & S & K & L & B & S & D & T & D & M & L & Y & W & H\end{array}$ AM MA TTG GA CTC GCA TCA TCC GeC TTA ACT AMA ATG GEC ATT GGT NGA TTA TCT ACA ATG CTT NCT ACC MT OCA ATT TTA MAG GA $\begin{array}{llllllllllllllllllllllllllllllll}K & K & L & E & L & A & S & S & G & L & T & K & M & G & I & G & R & L & S & T & M & L & T & T & N & A & I & L & K & E\end{array}$

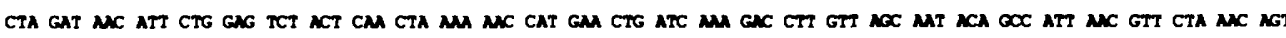

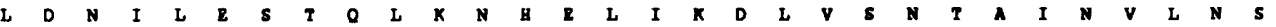
MA TAC TAT TCA AOG ФCT GAT CM GTT GAG MA TGT ATC MA COC TIC MG TAT GM ATT GAT TTG GM GM NGA GN TEG MOC CTT OCT

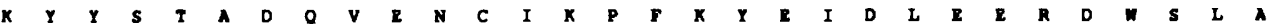

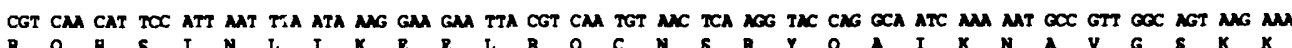

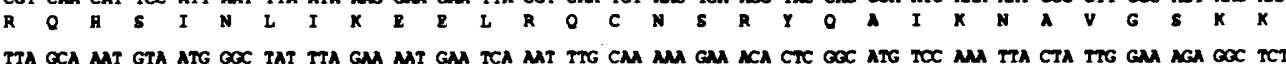

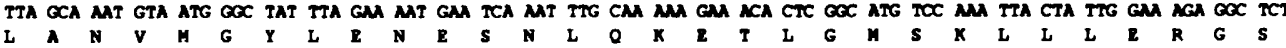

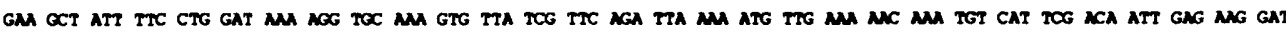
$\begin{array}{llllllllllllllllllllllllllllllll} & A & I & F & L & D & X & A & C & K & V & L & S & F & R & L & K & M & L & X & N & K & C & A & S & T & I & R & K & D\end{array}$

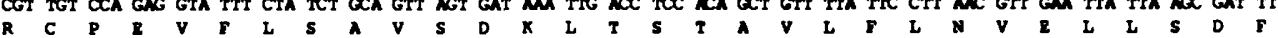

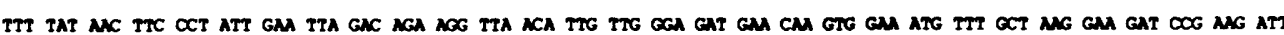

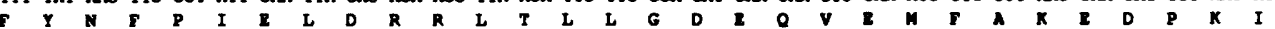

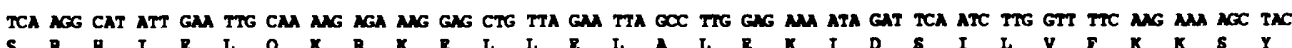

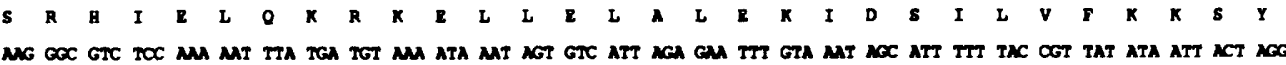

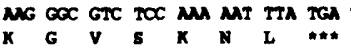

GTG TAT TTT TCT GM MM ATA MG OCA TAC CCT TCA TCT MG CTC TTT CTT ATA GTA IAC NG TCT CTT ATA TCE CAC GAT GTA ACA TCT MCA TAC TTC CTT TAT CGT CTT GM GA TM NCA MM GAT ATA TAT ATA TIA TTP TCT ATT ATT TRG GM GNG MT COT ATT CTT ACA GTA TEC NGA GAC ACA TCT GGT TET COT GTA GTT C

Figure 5. (See facing page for legend.)
78 168 56 258
86 348 116 438 146 618 206 


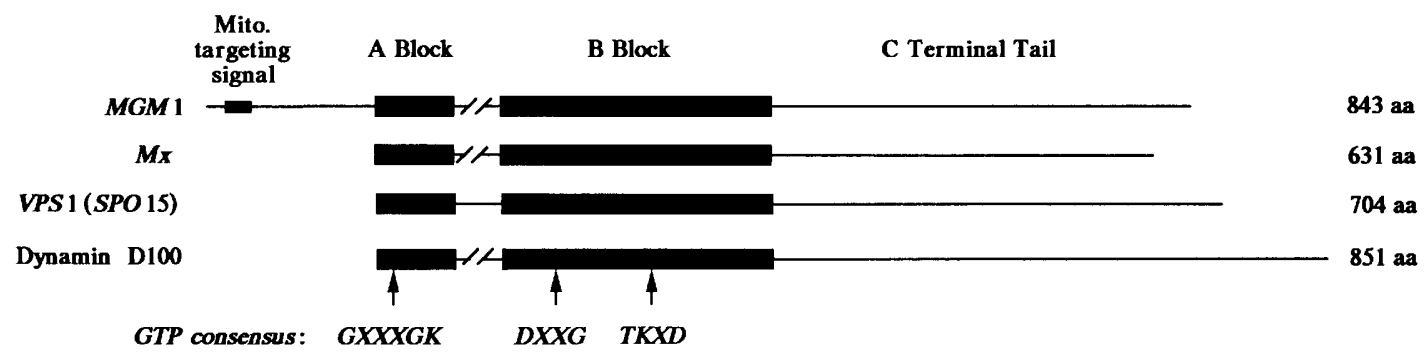

Figure 6. Schematic drawing showing the important functional regions of the four homologous proteins. In the mature form of MGM1, the import signal is probably proteolytically removed so that the A block would be near the amino terminus of the mature form of the protein as it is in the other three members of this family.

An interesting feature of these four proteins is that they are almost $100 \%$ identical in three regions within the $\mathrm{A}$ and $\mathrm{B}$ blocks that contain the consensus motif (GXXXXGK-DXXG-TKXD) of GTP-binding proteins (Dever et al. 1987; Rothman et al. 1990). The A block contains the first component VXGXQSXGKSSVLE, and the B block contains the other two, LXLXDLPG and RTIGVXTKXDLXD (Fig. 7). These sequences have the same spacing relative to each other in all four proteins.

\section{Discussion}

The MGM1 protein is related to a family of proteins of diverse function

The MGM1 gene product could function conceivably in the nucleus, controlling the synthesis of one or more mitochondrial proteins that must be supplied constantly to allow continued mtDNA replication. The MGM1 open reading frame, however, reveals an amino-terminal structure that is consistent with the protein being targeted to the mitochondrion. Based on map location and sequence, $M G M 1$ is distinct from three other genes that are required for mtDNA maintenance in yeast: $M I P 1$ codes for a mtDNA polymerase (Foury 1989), PPA2 encodes a mitochondrial pyrophosphatase (Lundin et al. 1991), and $A B F 2$ specifies a DNA-binding protein (Diffley and Stillman 1991). MIP1 is required for maintenance of both $\rho^{+}$and $\rho^{-}$mtDNAs, but whether PPA2 and $A B F 2$ are required by $\rho^{-}$mtDNAs is unknown. MGM1 is also distinct from the gene for mitochondrial RNA polymerase, $R P O 41$, which is required for maintenance of the integrity of the $\rho^{+}$genome but not for the cellular maintenance of $\rho^{-}$mtDNA (Fangman et al. 1990). It is unlikely that $M G M 1$ specifies a polymerase because no similarity is observed between the MGM1 protein and any of the conserved sequences present in other eukaryotic DNA polymerases (Argos 1988; Wong et al. 1988; Boulet et al. 1989) or RNA polymerases (Mas- ters et al. 1987). There are also no similarities to sequences found in many DNA-binding domains, such as zinc fingers, homeo domains, leucine zippers, or helixturn-helix regions (Mitchell and Tjian 1989).

The high degree of relatedness of the MGM1, $M x$, VPS1 (SPO15), and dynamin D100 proteins in an extensive region surrounding the GTP-binding motif is striking (Fig. 7). Except for the tripartite consensus itself, most other GTP-binding proteins share only limited homology (Dever et al. 1987). Apparently, the three components of the consensus sequence merely need to be in some proper orientation relative to the tertiary structure of the protein, and many different primary sequences are capable of providing that structure. The proteins of this dynamin family have diverse functions: mtDNA maintenance ( $M G M 1$; this report), resistance to influenza virus (MX; for review, see Arnheiter and Meier 1990), meiosis I and vacuole protein sorting (VPS1/SPO15; Rothman et al. 1990; Yeh et al. 1991), and endocytosis and microtubule sliding (dynamin D100; for review, see Collins 1991). A possible explanation for the more extensive relatedness of this family of proteins is that they share a function beyond GTP binding and hydrolysis. One proposal, based on a presumed mechanochemical motor activity of dynamin D100, is that the GTP-binding region of the proteins associates with microtubules and uses GTP hydrolysis to generate motive force. In this view, the common function of these proteins is to move materials to different cellular compartments as dictated by their unrelated carboxy-terminal halves (Obar et al. 1990). The evidence, however, that dynamin is a microtubule motor is not complete (for review, see Collins 1991). Furthermore, microtubules have not been detected in the mitochondrion where the MGM1 protein most likely functions in yeast, although fibrous structures have been demonstrated in this organelle (Yotsuyanagi 1988).

Finding a protein that is likely localized to the mitochondrion and that is a member of the dynamin family

Figure 5. The open reading frame of the MGM1 gene. The underlined nucleotide sequence is $\sim 0.5 \mathrm{~kb}$ from the start of the $S T E 4$ gene. MGM1 and STE4 have opposite sense strands (Whiteway et al. 1989). The underlined amino acids represent the location of the proposed mitochondrial targeting amphiphilic helix. The double underlined amino acids indicate the location of the three GTP consensus-binding sites. 


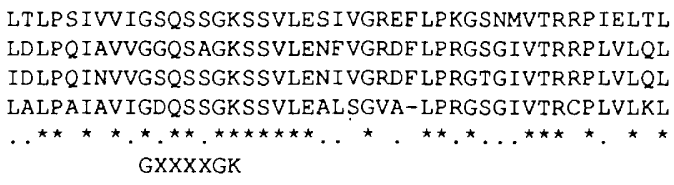

LDLPQIAVVGGQSAGKS SVLENFVGRDF LPRGSGIVTRRPLVLOL

ID LPQ INVVGSQS SGKSSVLEN I VGRDF LPRGTG IVTRRP LVLQL

GXXXXGK

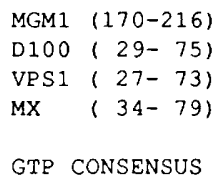

D100 (29- 75$)$

S1 (27-73)

GTP CONSENSUS

\section{A BLOCK}

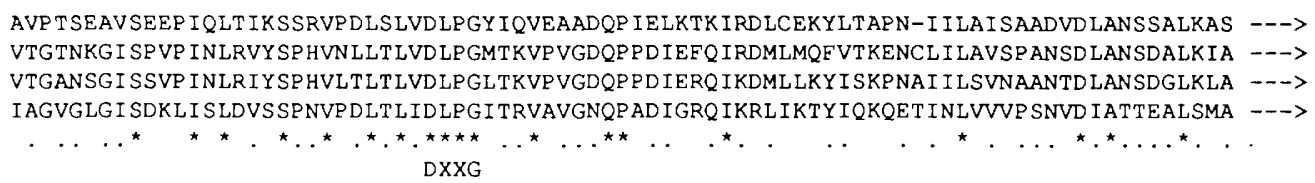

AVPTSEAVSEEPIQLTIKSSRVPDLSLVDLPGYIQVEAADQPIELKTKIRDLCEKYLTAPN-IILAISAADVDLANSSALKAS ---> VTGTNKG I SPVP INLRVY SP HVNLLT LVDLPGMTKVPVGDQP PD IEFQ IRDMLMQFVTKENCLI LAVSPANSDLANSDALKIA -- -> VTGANSGI SSVP INLRIYSPHVLTLT LVDLPGLTKVPVGDQP PD IERQ IKDML LKYISKPNAI ILSVNAANTD LANSDGLKLA -- -> I AGVGLG I SDKL I SLDVSSP NVP DLT L IDLPGI TRVAVGNQP AD I GRQ IKRL I KTY IQKQET INLVVVP SNVD IATTEALSMA --->

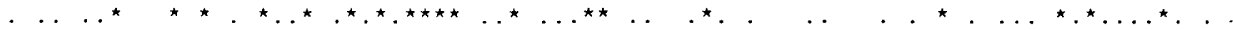
DXXG

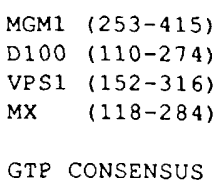

MGM1 (253-415)

D100 (110-274)

VPS1 $(152-316)$

GTP CONSENSUS

\section{B BLOCK}

Figure 7. Alignment of the MGM1 amino acid sequence with dynamin D100, VPS1 (SPO15), and mouse Mx. The A block is 46 amino acids long and is separated from the B block by a nonhomologous region that is 37 amino acids long. The single exception is VPS1, which has a total of 79 amino acids between the two blocks of homology. An asterisk (*) is placed below the sequence when all four proteins are identical and a dot $(\cdot)$ when the change is conserved. The GTP-binding consensus is also indicated. The human and fish forms of $M x$ and the Drosophila dynamin are not shown. Their homologies with the MGM1 protein are not significantly different from those with the $M x$ and dynamin proteins that are shown.

leads us to propose a different model in which the common function performed by the related amino-terminal halves of these proteins is transmission of a signal to the carboxy-terminal halves by GTP binding and hydrolysis. In this view, the carboxy-terminal half of each protein would be responsible for a function that is specific to that protein and whose activity is controlled by interactions with the amino-terminal half (Fig. 6). The common amino-terminal region corresponds to a protein of $\sim 32$ $\mathrm{kD}$, similar in size to two other GTP-binding families, G proteins $(\sim 40 \mathrm{kD})$, and Ras proteins $(\sim 20 \mathrm{kD})$. The nonrelated carboxy-terminal halves range in size from $39 \mathrm{kD}$ for $M x$ to $64 \mathrm{kD}$ for dynamin D100, large enough to have enzymatic activities or structural roles of their own. In fact, the carboxy-terminal part of the MGM1 protein is required for function, as deletion of $80-88$ amino acids from the carboxyl terminus eliminates complementation of the mgm1-1 mutation (p $\Delta 54$; see Fig. 1). By allowing many large gaps in the sequence comparison, it has been proposed that the carboxyl termini of VPS1 and D100 are significantly related (Obar et al. 1990). Therefore, of those proteins in the family known currently, only VPS1 and D100 are likely to have a related function.

\section{Implications for mtDNA metabolism}

The analysis of mutant mgm1-1 shows that net synthesis of mtDNA ceases at the restrictive temperature, with chondriolites being partitioned more or less equally during subsequent cell divisions. The simplest explanation for these observations is that the mgm1-1 mutation results in a defect in mtDNA replication. Balanced degradation and synthesis of mtDNA remains a possibility, but seems unlikely. Treatments with agents, such as ethidium bromide (Nagley and Linnane 1972), that cause degradation of mtDNA, result first in the production of stable $\rho^{-}$deletion variants. After plating onto medium without ethidium bromide, $\rho^{-}$variants are observed as respiration-deficient colonies containing normal amounts of mtDNA but lacking most $\rho^{+}$sequences. With continued incubation with ethidium bromide, cells completely lacking mtDNA $\left(\rho^{\circ}\right)$ are produced. If the mgm1-1 strain produced $\rho^{-}$intermediates, then the first white colonies to be produced after incubation at $34^{\circ} \mathrm{C}$ should be $\rho^{-}$. Examination of many respiration-deficient mgm1-1 colonies provided no evidence for such $\rho^{-}$intermediates; every clone examined was $\rho^{\circ}$.

The properties of the $m g m 1-1$ strain at $34^{\circ} \mathrm{C}$ may provide insights into the nature of mtDNA segregation and amplification in yeast. The first appearance of respiration-deficient colonies should correspond to the time when there is on average only one functional unit remaining in each cell in the population. A functional unit is defined as the material sufficient to restore respiration competence. This unit could consist of one or more mtDNA molecules, depending on whether individual molecules segregate or a cluster of a few clonally derived 
molecules segregate together, or on how many molecules are required to establish respiration competence when cells are returned to the permissive temperature. The observed lag of $4.0-4.25$ generations would be sufficient to dilute 16-19 units to 1 unit per cell. These values are close to the number of mtDNA molecules in a mgm1-1 cell grown under our culture conditions. Thus, it would appear that under these conditions, yeast cells partition their complement of mitochondrial genomes until a single mtDNA molecule is being distributed at cell division. This finding is surprising in light of the segregation behavior observed when zygotes are formed by mating two cells with differently marked mitochondrial genomes. The heteroplasmic state is unstable, and within a few generations only homoplasmic cells, those with a single type of mitochondrial genome, remain. This postzygotic segregation is much too rapid to be accounted for by random partitioning of the original mtDNA molecules (for review, see Birky 1978). The segregation could be explained, however, if there was a smaller number of segregating units, each composed of more than one mtDNA molecule. But our results indicate that, at least for vegetative cells, segregating units need not consist of multiple molecules. They also indicate that a single molecule can be detected and amplified by the copy number control system.

\section{Materials and methods}

\section{Yeast strains and genetic manipulations}

All of the strains used for this study were congenic to A364A (Hartwell 1967), with the exception of those used for mapping and for deletion of MGM1 in a $\rho^{-}$background: BS127 [MATa, ade1, ade2, ura3-52, leu2-3,112, trp1-289, $C Y H^{\mathrm{r}}, C A N^{\mathrm{x}}$, gal $\left.|-|\right]$ and BS132 [MATa, ade1, ade2, ura3-52, leu2-3,112, tyr1, lys2, his7] from R. Sclafani; 4a and HS3324 [MATa, his1, trp2, leu2, $\rho^{-}$] (Fangman et al. 1989); BJ96-13b [MATa, tyr1, met7, mgm11], BJ97-3a [MATa, ade1, ade2, ura3-52, his3, arg8, trp1, asp5], BJ72-10 [MATa, ade1, ade2, ura3-52, leu2-3,112, bar1, his6], and BJ89-4d [MATa, ade1, ade2, ura3-52, leu2-3,112, bar1, his6, mgm1-1] from this work. Except where noted, standard yeast genetics methods were used (Mortimer and Hawthorne 1969).

For the mutant screen, the haploid strain BS127 was mutagenized at $23^{\circ} \mathrm{C}$ with EMS (Sherman et al. 1979). Cells treated for $30 \mathrm{~min}$, to $50 \%$ viability, were plated on YEP-glycerol plates and incubated at $23^{\circ} \mathrm{C}$ for 5 days. Primary colonies from these glycerol plates were streaked on YEP-glucose plates to obtain individual colonies, and plates were incubated at $36^{\circ} \mathrm{C}$ for 3-7 days. A secondary white colony from each of the streaks that displayed a high proportion of white colonies and/or sectors at $36^{\circ} \mathrm{C}$ was restreaked on glucose plates that were then incubated at $23^{\circ} \mathrm{C}$ for $4-5$ days. White colonies from the $23^{\circ} \mathrm{C}$ plates were stained with 4',6-diamidino-2-phenylindole (DAPI). If cells from the white colony had cytoplasmic staining typical of mtDNA, the primary mutant clone was discarded. If there was no cytoplasmic staining, the original clone was considered a possible mutant with a defect in nuclear gene required for mtDNA maintenance. From the original glycerol plates, each of the potential mutants was used to inoculate a liquid YEP-glycerol culture, which was grown overnight at $23^{\circ} \mathrm{C}$. A small sample of each culture was plated at $23^{\circ} \mathrm{C}$, and liquid YEP-glucose cultures were grown at $23^{\circ} \mathrm{C}$ and at $36^{\circ} \mathrm{C}$. When the cultures reached stationary phase (five to eight generations), samples were plated on glucose plates and grown at $23^{\circ} \mathrm{C}$. Mutant strains that produced a high frequency $(\sim 60-100 \%)$ of white colonies when plated from $36^{\circ} \mathrm{C}$ cultures were selected for further study.

\section{Media and culture conditions}

Liquid and solid yeast media are as described previously (Hartwell 1967; Wood 1982). The only exception to the standard media was in the temperature-shift experiments used to determine the rate of petite production: Cells were grown overnight (at least eight generations) in YEP with $10 \%$ glucose to minimize the difference in growth rates normally observed between wild-type and respiration-deficient cells. Exponential cultures were diluted in fresh prewarmed YEP/ $10 \%$ glucose and placed at $34-35^{\circ} \mathrm{C}$. During the course of the experiment, fresh prewarmed media were added so that the cultures remained in log-phase growth; typically, cells were diluted to $5 \times 10^{6} \mathrm{cells} / \mathrm{ml}$ and allowed to grow until they reached $2 \times 10^{7}$ cells $/ \mathrm{ml}$. At the appropriate time intervals, samples were taken, diluted, and plated on YEPD plates that were incubated at $23^{\circ} \mathrm{C}$.

\section{DAPI staining and fluorescence microscopy}

Cells were centrifuged out of liquid cultures or picked from colonies, fixed with $100 \%$ methanol for $5 \mathrm{~min}$, washed with PBS $\left[0.5 \mathrm{M} \mathrm{KPO}_{4}\right.$ and $\left.1.0 \% \mathrm{NaCl}(\mathrm{pH} 7.4)\right]$, resuspended in $1 \mu \mathrm{g} / \mathrm{ml}$ of DAPI, and incubated at $4^{\circ} \mathrm{C}$ until it was convenient to examine them ( $5 \mathrm{~min}$ to 1 week). DAPI-stained cells were examined with a fluorescence microscope (Nikon Microphot-FX) using a $60 \times$ oil immersion objective. The barrier filter was BA420, and the dichromic mirror was DM400. Pictures were taken with 10sec exposures on Kodak Tech-pan film, ASA 160.

\section{DNA isolation and characterization}

Total yeast DNA was prepared by the guanidine- $\mathrm{HCl}$ protocol (Holm et al. 1986). The DNA was serially diluted twofold in a microtiter dish and incubated for $1 \mathrm{hr}$ at $68^{\circ} \mathrm{C}$ with $0.4 \mathrm{~N} \mathrm{NaOH}$ (final concentration) to hydrolyze any RNA present and denature the DNA. An equal volume of $20 \times \mathrm{SSC}(3 \mathrm{M} \mathrm{NaCl}$ and 0.3 $M$ sodium citrate) was added to the denatured DNA and filtered by vacuum onto a Nytran filter using slot-blot apparatus (Schleicher and Schuell). DNA was cross-linked to the Nytran with $1200 \mathrm{~J}$ of UV light using a UV Stratalinker (Stratagene). DNA for Southern blots of restriction endonuclease-digested genomic DNAs and for recovery of plasmids from yeast clones was prepared by the quick technique of Hoffman and Winston (1987). Isolated DNA fragments were labeled with $\left[\alpha^{-32} \mathrm{P}\right] \mathrm{dATP}$ $(6000 \mathrm{Ci} / \mathrm{mmole}$, New England Nuclear) by random hexanucleotide primer extension (Feinberg and Vogelstein 1983). Unincorporated nucleotides were removed by the Sephadex G-50 procedure (Maniatis et al. 1982). Probes were denatured immediately before hybridization by boiling for $5 \mathrm{~min}$.

Nytran filters were hybridized by the high phosphate method of Church and Gilbert (1984). Exposures were made on Kodak XR-5 film with a Dupont Cronex Lighting Plus intensifying screen at $-70^{\circ} \mathrm{C}$. Blots were stripped by washing twice at $68^{\circ} \mathrm{C}$ for $20 \mathrm{~min}$, then with a boiling solution of $10 \mathrm{mM}$ Tris- $\mathrm{HCl} / \mathrm{pH}$ $8.0), 1 \mathrm{mM}$ EDTA, and 1\% SDS. Care was taken that filters never dried out so that the probes were not irreversibly bound. Appropriate exposures of the autoradiographs were scanned using a Quick Scan Jr. densitometer (Helena Laboratories). The number of mtDNA molecules per cell was determined by quantitative slot hybridization, using as a standard a total DNA prepa- 
ration in which the absolute ratio of mtDNA to nuclear DNA had been determined (Fangman et al. 1989).

\section{Cloning and sequencing manipulations}

The yeast strain BJ41-8c (mgm1-1) was grown overnight in YEPD at $23^{\circ} \mathrm{C}$; plasmids containing random inserts from wildtype yeast chromosomal were introduced by a spheroplast transformation (Hinnen et al. 1978). The library that gave rise to a successful clone was RB112 (URA3, $2 \mu$ origin, $\left.\mathrm{Amp}^{\mathrm{r}}\right)$ (Carlson and Botstein 1982). The cells were plated on glycerol plates minus uracil (to select for transformants) at $36^{\circ} \mathrm{C}$ (to select for MGM1 function). Subsequent constructs were introduced by the lithium acetate transformation procedure (Ito et al. 1983).

The overlap of the MGM1 clone with the RET1/PTP1 and $S T E 4$ clones was recognized initially by restriction site patterns and proven by a combination of sequence analysis and Southern hybridizations using fragments of each clone as a probe. Southern hybridizations showed that the cloned insert containing MGM1 was present in the yeast chromosome in single copy and with the same restriction map as in the clone. The orientation relative to HIS3 (centromere side) and MET7 (telomere side) was determined because the other end of the RET1/PTP1 clone overlapped with the HIS3 clone (James et al. 1991).

MGM1 was deleted by the one-step disruption technique of Rothstein (1983). Two of the plasmids used in sequencing, pI12 and pIl0, were cut with HpaI and HindIII. The appropriate bands were isolated from a gel and ligated to form $\mathrm{pBJ} \Delta \mathrm{H}$. The resulting plasmid was opened up with $\mathrm{HpaI}$, and a HpaI-SmaI $U R A 3$ fragment from YEp352 was ligated in to form $\mathrm{pBJ} 16$. The deleted region begins $300 \mathrm{bp} 5^{\prime}$ of the first methionine and leaves only the carboxy-terminal 55 amino acids of the original protein. When pBI16 is cut with MluI and AhaII, it yields a linear fragment containing URA3 flanked by DNA that normally flanks $M G M 1$. This linear fragment was transformed into a MGM1 strain, and transformants were selected on plates minus uracil.

$\mathrm{p} \Delta \mathrm{I}$, the complementing plasmid that contained the least amount of non-MGM1 DNA (see Results), was used to construct a series of plasmids for sequencing the MGM1 gene. A PstI digest of $\mathrm{p} \Delta \mathrm{I}$ cut the mom1-1 complementing region into three separate fragments. Each of these fragments was cloned in both possible orientations into pGEM-4 (Promega) to form plasmids I10, I11, I12 , I20, I21, and I22. Each of these six plasmids was opened up with an enzyme (KpnI or SstI) that leaves a $3^{\prime}$ overhang that cannot be used as a substrate for exonuclease III degradation. They were then cut with an enzyme (BamHI or $X b a I)$ that leaves a $5^{\prime}$ overhang adjacent to the MGM1-coding region. The $5^{\prime}$ overhang is a substrate for exonuclease III. Exonuclease III was added, and samples were taken at 30-sec intervals during incubation at $37^{\circ} \mathrm{C}$. Any single-stranded regions left from exonuclease III treatment were removed with S1 nuclease, small gaps were filled with Klenow polymerase, and the plasmids were recircularized with T4 DNA ligase and transformed into bacteria (Henikoff 1984). A series of plasmids containing progressively bigger deletions, in $\sim 200$-bp increments, was obtained. An oligonucleotide complementary to the SP6 promoter was used as the primer for sequencing. Sequencing reactions with Sequenase and ${ }^{35} S$-labeled dATP were performed according to the manufacturer (U.S. Biochemical). Reactions were loaded on a $6 \%$ acrylamide gel (Biggin et al. 1983) and run at $1500 \mathrm{~V}$ for 2-6 hr. Gels were transferred to Whatman 3MM paper and exposed using Kodak XR-5 film at room temperature. Under these conditions, a typical run would yield $150-250$ bases of sequence information. There were a few places where the appropriate deletion was not present in the plasmid collection. To fill in these gaps, the restriction sites determined by previous runs were used to make plasmids with the desired sequence adjacent to the SP6 promoter. To prove that there were not two closely spaced PstI sites that could have resulted in a small fragment being lost during the construction of pI10-I22, oligonucleotides complementary to the appropriate regions were used to prime sequencing reactions across the PstI sites in the original plasmid, $\mathrm{pKa}-1$.

\section{Acknowledgments}

We thank Bonita Brewer, Brian Corner, Teresa Ward, and Stephan Zweifel for their suggestions and support during the course of this study and for criticizing the manuscript. This work was supported by National Science Foundation grant DMB-8408712 and U.S. Public Health Services grant GM43847. B.A.J. was supported during part of this work by a U.S. Public Health Service training grant.

The publication costs of this article were defrayed in part by payment of page charges. This article must therefore be hereby marked "advertisement" in accordance with 18 USC section 1734 solely to indicate this fact.

\section{Note added in proof}

Sequence data described in this paper have been submitted to the EMBL/GenBank data libraries under accession no. X62834 SCMGMDNA.

\section{References}

Argos, P. 1988. A sequence motif in many polymerases. Nucleic Acids Res. 16: 9909-9916.

Arnheiter, H. and E. Meier. 1990. Mx Proteins: Antiviral by chance or by necessity? The New Biologist 2: 851-857.

Biggin, M.D., T.J. Gilson, and G.F. Honget. 1983. Buffer gradient gels and ${ }^{35} \mathrm{~S}$ label as an aid to rapid DNA sequence determination. Proc. Natl. Acad. Sci. 80: 3963-3965.

Birky, C.W., Jr. 1978. Transmission genetics of mitochondria and chloroplasts. Annu. Rev. Genet. 12: 471-512.

Boulet, A., M. Simon, G. Faye, G.A. Bauer, and P.M. Burgers. 1989. Structure and function of the Saccharomyces cerevisiae CDC2 gene encoding the large subunit of DNA polymerase III. EMBO I. 8: 1849-1854.

Carle, G.F. and M.V. Olson. 1984. Separation of chromosomal DNA molecules from yeast by orthogonal-field-alternation gel electrophoresis. Nucleic Acids Res. 12: 5647-5664.

Carlson, M. and D. Botstein. 1982. Two differentially regulated mRNAs with different $5^{\prime}$ ends encode secreted and intracellular forms of yeast invertase. Cell 28: 145-154.

Chen, M.S., R.A. Obar, C.C. Schroeder, T.W. Austin, C.A. Poodry, S.C. Wadsworth, and R.B. Vallee. 1991. Multiple forms of dynamin are encoded by shibire, a Drosophila gene involved in endocytosis. Nature 351: 583-586.

Church, G.M. and W. Gilbert. 1984. Genomic sequencing. Proc. Natl. Acad. Sci.81: 1991-1995.

Collins, C.A. 1991. Dynamin, a microtubule associated GTPase with homology to a new family of GTP binding proteins. Trends Cell Biol. 1: 57-60.

Dever, T.E., M.J. Glynias, and W.C. Merrick. 1987. GTP-binding domain: Three consensus sequence elements with distinct spacing. Proc. Nat1. Acad. Sci.84: 1814-1818.

Diffley, J. F. X. and B. Stillman. 1991. A close relative of the nuclear, chromosomal high-mobility group protein HMG1 in yeast mitochondria. Proc. Natl. Acad. Sci. 88: 7864-7868. 
Ephrussi, B. and H. Hottinguer. 1951. Cytoplasmic constituents of heredity. On an unstable state in yeast. Cold Spring Harbor Symp. Quant. Biol. 16: 75-85.

Fangman, W.L., J.W. Henly, G. Churchill, and B.J. Brewer. 1989. Stable maintenance of a 35-base-pair yeast mitochondrial genome. Mol. Cell. Biol. 9: 1917-1921.

Fangman, W.L., J.W. Henly, and B.J. Brewer. 1990. RPO41-independent maintenance of [rho-] mitochondrial DNA in Saccharomyces cerevisiae. Mol. Cell. Biol. 10: 10-15.

Feinberg, A.P. and B. Vogelstein. 1983. A technique for radiolabeling DNA restriction endonuclease fragments to high specific activity. Anal. Biochem. 132: 6-13.

Foury, F. 1989. Cloning and sequencing of the nuclear gene MIP1 encoding the catalytic subunit of the yeast mitochondrial DNA polymerase. J. Biol. Chem. 264: 20552-20560.

Gavel, Y., L. Nilsson, and G. von Heijne. 1988. Mitochondrial targeting sequences: Why "non-amphiphilic" peptides may still be amphiphilic. FEBS Letts. 235: 173-177.

Hartl, F.U. and W. Neupert. 1990. Protein sorting to mitochondria: Evolutionary conservations of folding and assembly. Science 247: 930-938.

Hartwell, L.H. 1967. Macromolecule synthesis in temperaturesensitive mutants of yeast. J. Bacteriol. 93: 1662-1670.

Henikoff, S. 1984. Unidirectional digestion with Exonuclease III creates targeted breakpoints for DNA sequencing. Gene 28: 351-359.

Hinnen, A., J.B. Hicks, and G.R. Fink. 1978. Transformation of yeast. Proc. Natl. Acad. Sci. 75: 1929-1933.

Hoffman, C.S. and F. Winston. 1987. A ten-minute DNA preparation from yeast efficiently releases autonomous plasmids for transformation of Escherichia coli. Gene 57: 267-272.

Holm, C., D.W. Meeks-Wagner, W.L. Fangman, and D. Botstein. 1986. A rapid, efficient method for isolating DNA from yeast. Gene 42: 169-173.

Ito, H., Y. Fukada, K. Murata, and A. Kimura. 1983. Transformation of intact yeast treated with alkali cations. J. Bacteriol. 153: 163-168.

James, P., S. Whelen, and B.D. Hall. 1991. The RET1 gene of yeast encodes the second-largest subunit of RNA polymerase III: Structural analysis of the wild type and ret1-1 mutant alleles. J. Biol. Chem. 266: 5616-5624.

Lundin, M., H. Baltscheffsky, and H. Ronne. 1991. Yeast PPA2 gene encodes a mitochondrial inorganic pyrophosphatase that is essential for mitochondrial function. J. Biol. Chem. 266: 12168-12172.

Maniatis, T., E.F. Fritsch, and J. Sambrook. 1982. Molecular cloning: A laboratory manual. Cold Spring Harbor Laboratory, Cold Spring Harbor, New York.

Masters, B.S., L.L. Stohl, and D.A. Clayton. 1987. Yeast mitochondrial RNA polymerase is homologous to those encoded by bacteriophages T3 and T7. Cell 51: 89-99.

Mattick, J. and P. Nagley. 1977. Comparative studies of the effects of acridines and other petite inducing drugs on the mitochondrial genome of Saccharomyces cerevisiae. Mol. Gen. Genet. 152: 267-276.

Mitchell, P.J. and R. Tjian. 1989. Transcriptional regulation in mammalian cells by sequence-specific DNA binding proteins. Science 245: 371-378.

Mortimer, R.K. and D.C. Hawthorne. 1969. Yeast genetics. In: The yeasts (ed. A.H. Rose and J.S. Harrison), vol. 1, pp. 385460. Academic Press, New York.

Nagley, P. and A.W. Linnane. 1972. Biogenesis of mitochondria. XXI. Studies on thenature of the mitochondrial genome in yeast: The degenerative effects of ethidium bromide. J. Mol. Biol. 66: 181-193.

Obar, R.A., C.A. Collins, J.A. Hammarback, H.S. Shpetner, and
R.B. Vallee. 1990. Molecular cloning of the microtubule-associated mechanochemical enzyme dynamin reveals homology with a new family of GTP-binding proteins. Nature 347: 256-261.

Reaume, S.E. and E.L. Tatum. 1949. Spontaneous and nitrogen mustard induced nutritional deficiencies in Saccharomyces cerevisiae. Arch. Biochem. 22: 331-338.

Rothman, J.H., C.K. Raymond, T. Gilbert, P. O'Hara, and T. Stevens. 1990. A putative GTP binding protein homologous to interferon-inducible $\mathrm{Mx}$ proteins performs an essential function in yeast protein sorting. Cell 61: 1063-1074.

Rothstein, R.J. 1983. A one step gene disruption in yeast. Methods Enzymol. 101: 202-211.

Sherman, F., G.R. Fink, and C. Lawerence. 1979. Methods in yeast genetics: Laboratory manual. Cold Spring Harbor Laboratory, Cold Spring Harbor, New York.

Tzagoloff, A. and C.L. Dieckmann. 1990. PET genes of Saccharomyces cerevisae. Microbiol. Rev. 54: 211-225.

van der Bliek, A.M. and E.M. Meyerowitz. 1991. Dynamin-like protein encoded by the Drosophila shibire gene associated with vesicular traffic. Nature 351: 411-414.

von Heijne, G. 1986. Mitochondrial targeting sequences may form amphiphilic helices. EMBO I. 5: 1335-1342.

Whiteway, M., L. Hougan, D. Dignard, D.Y. Thomas, L. Bell, G.C. Saari, F.J. Grant, P. O'Hara, and V.L. MacKay. 1989. The STE 4 and STE18 genes of yeast encode potential $\beta$ and $\gamma$ subunits of the mating factor receptor-coupled $G$ protein. Cell 56: 467-477.

Williamson, D.H. 1976. Packaging and recombination of mitochondrial DNA in vegetatively growing yeast cells. In $G e$ netics, biogenesis and bioenergetics of mitochondria (ed. W. Bandlow, R.J. Scheweyen, D.Y. Thomas, K. Wolf, and F. Kaudewitz), p.117. de Gruyter, Berlin, Germany.

Williamson, D.H. and D.J. Fennell. 1979. Visualization of yeast mitochondrial DNA with the fluorescent stain "DAPI." Methods Enzymol. 56: 728-733.

Wong, S.W., A.F. Wahl, P. Yuan, N. Arai, B.E. Pearson, K. Arai, D. Kom, M.W. Hunkapiller, and T. Wang. 1988. Human DNA polymerase $\alpha$ gene expression is cell proliferation dependent and its primary structure is similar to both prokaryotic and eukaryotic replicative DNA polymerases. EMBO $\%$. 7: $37-47$

Wood, J.S. 1982. Genetic effects of methyl benzimadole-2-ylcarbamate on Saccharomyces cerevisiae. Mol. Cell. Biol. 2: 1064-1079.

Yeh, E., R. Driscol, M. Coltrera, A. Olins, and K. Bloom. 1991. A dynamin-like protein encoded by the yeast sporulation gene SPO15. Nature 349: 713-715.

Yotsuyanagi, Y. 1988. Fibrous component of yeast mitochondria. J. Ultra. Mol. Struct. Res. 98: 254-266. 


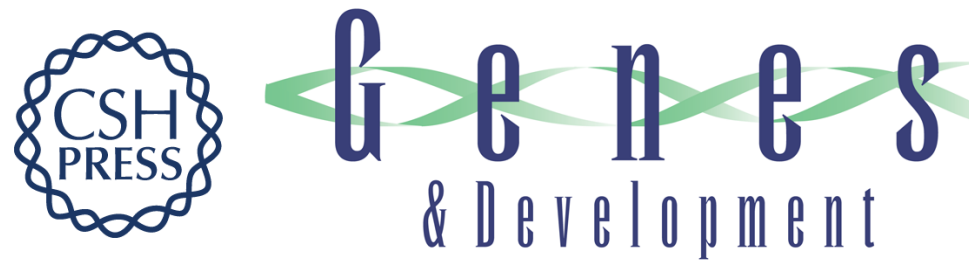

\section{Mitochondrial DNA maintenance in yeast requires a protein containing a region related to the GTP-binding domain of dynamin.}

B A Jones and W L Fangman

Genes Dev. 1992, 6:

Access the most recent version at doi:10.1101/gad.6.3.380

References This article cites 44 articles, 17 of which can be accessed free at:

http://genesdev.cshlp.org/content/6/3/380.full.html\#ref-list-1

License

Email Alerting

Service

Receive free email alerts when new articles cite this article - sign up in the box at the top right corner of the article or click here.

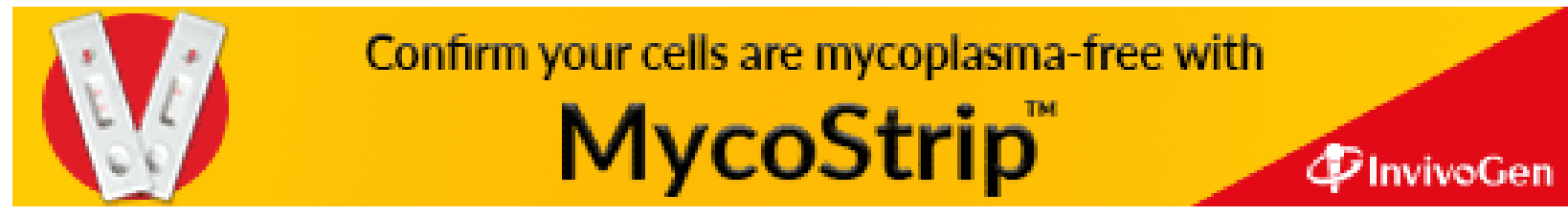

